\title{
Batería III Woodcock-Muñoz
}

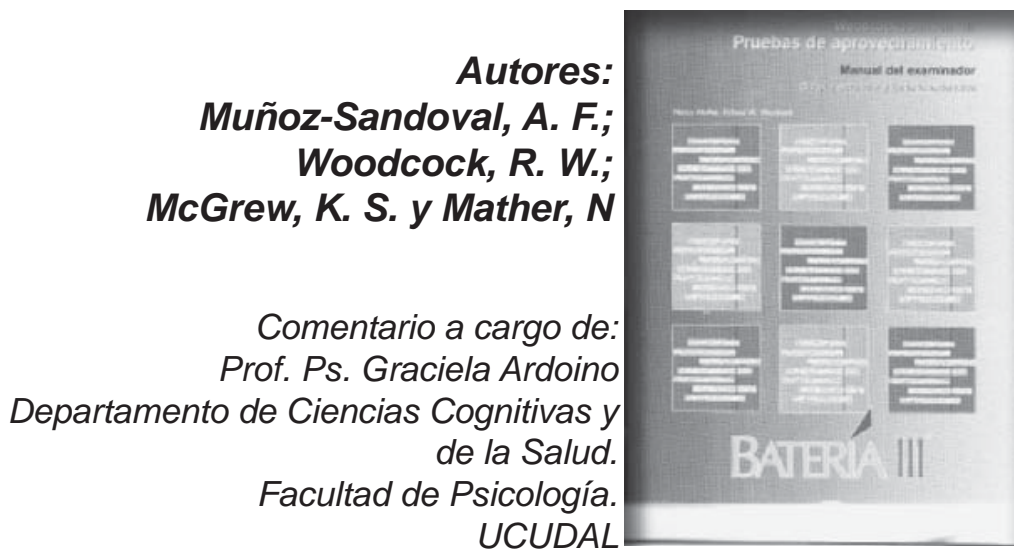

\section{Ficha Técnica}

\begin{tabular}{|l|l|}
\hline Nombre: & Batería III Woodcock-Muñoz \\
\hline Autores: & $\begin{array}{l}\text { Muñoz-Sandoval, A. F.; Woodcock, R. W.; } \\
\text { McGrew, K. S. y Mather, N }\end{array}$ \\
\hline Editorial: & Itasca. IL: Riverside Publishing \\
\hline $\begin{array}{l}\text { Ámbito de } \\
\text { aplicación: }\end{array}$ & $\begin{array}{l}\text { Niños desde los } 2 \text { años a adultos } \\
\text { mayores 90 años }\end{array}$ \\
\hline Administración: & $\begin{array}{l}\text { Individual. El tiempo de administración de cada } \\
\text { tests varía entre los 5 - 10 minutos. El tiempo } \\
\text { total de administración de la Batería III depende } \\
\text { del número de pruebas elegidas para aplicar }\end{array}$ \\
\hline Baremos: & $\begin{array}{l}\text { Provenientes de Estados Unidos. } \\
\text { Presenta normas de edad y de grado escolar }\end{array}$ \\
\hline
\end{tabular}

La Batería III es la versión desarrollada de modo paralelo en idioma español, del WoodcockJohnson III $^{1}$ (la primera versión data de $1977^{2}$ ). Se trata de una técnica de amplio uso internacional tanto en la evaluación educacional, clínica como en investigación. Para su traducción y adaptación se trabajó con 1.413 personas, residentes en Estados Unidos y en países de habla hispana, cuyo primer idioma era el español.

Basado en la teoría de las habilidades cognitivas de Cattell y Horn (inteligencia fluida y cristalizada) y de Carroll (tres estratos que representan un factor general " $g$ ", habilidades amplias y habilidades específicas) conocida como teoría CHC; y los modelos WJ III de rendimiento cognitivo y procesamiento de la información.

Constituida por un total de 42 tests, agrupados en Pruebas de Habilidades Cognitivas (Batería III COG) y Pruebas de Aprovechamiento (Batería III-APROV).

La Bateria III-COG comprende 20 tests, de los cuales los 10 primeros constituyen la batería estándar y los últimos 10 la batería extendida.

Las pruebas de la batería III-APROV son en total 22, siendo las 12 primeras las que corres-

1 Woodcock, R.W.; McGrew, K.S. y Mather, N (2001): Woodcock-Johnson III. Itasca, IL: Riverside Publishing 2 Frank de Verthelyi, Renata (1999). El análisis intra e intertest en la evaluación cognitiva: aportes del WoodcockMuñoz, R. a la batería cognitiva. RIDEP, 1. 
ponden a la batería estándar y las 10 restantes a la batería extendida.

Una de las riquezas de este instrumento, está justamente en el alto número de tests que lo integran y la flexibilidad que permite al profesional elegir qué necesita administrar de acuerdo a sus intereses técnicos.

Además de la puntuación de cada uno de los tests administrados, la Batería III nos proporciona una serie de puntuaciones compuestas, fundamentales para la interpretación de los resultados con mayor seguridad.

Entre las puntuaciones compuestas que surgen de la Batería III COG está el Aprovechamiento predicho (predice el grado de aprovechamiento académico en lectura, matemática, lenguaje escrito y oral y conocimientos académicos); la Habilidad intelectual general ( $\mathrm{g}$ ) y la Habilidad intelectual breve (medida concisa y confiable de la inteligencia), útil cuando no es necesario realizar una evaluación más profunda.

También pueden obtenerse puntuaciones compuestas de rendimiento cognitivo y de los factores $\mathrm{CHC}$.

Las puntuaciones compuestas correspondientes a la Batería III APROV son: Lectura, Lenguaje oral, Matemáticas, Lenguaje escrito, Conocimientos académicos, entre otras.

Con un fuerte respaldo psicométrico, presenta normas de edad y de grado que permiten obtener sus puntaciones equivalentes, así como, puntuación W (puntuaciones promedio de las pruebas incluidas en cada puntuación compuesta), índice de proficiencia relativa (RIP), rango percentil y puntuación estándar.

Cuenta con un programa computarizado (Compuscore and Profiles), que permite obtener las diversas puntuaciones que acompañan el análisis cualitativo de la técnica y un breve reporte.

En suma, se puede hacer referencia al Woodcock-Muñoz como una Batería que incluye un conjunto de pruebas para medir el desarrollo cognitivo y la predicción de logro académico. 